\title{
CIRCE-ICE PLOHS EXPERIMENTAL CAMPAIGN
}

\author{
D. Martelli ${ }^{\circ}, \mathrm{M}$. Tarantino $^{\circ}$, N. Forgione* \\ * University of Pisa, Department of Civil and Industrial Engineering, Pisa, Italy \\ ${ }^{\circ}$ ENEA FSN-ING, Brasimone R.C., Camugnano (Bo), 40033, Italy \\ Corresponding author: daniele.martelli@enea.it
}

\begin{abstract}
In the framework of the Heavy Liquid Metal (HLM) - GEN IV Nuclear reactor development one of the main tasks deals with the thermal-hydraulics analysis of Heavy Liquid Metal (HLM) cooled fast reactors (attention mainly focused on LBE and Lead-cooled reactors), aimed at their safety analysis in response to a hypothetical accidental scenario.

To support this task, the experimental campaign on the CIRCE-ICE configuration (funded by the EU project SESAME WP3) was developed and accomplished at the ENEA Brasimone Nuclear laboratory. The dataset produced represents a database for thermal hydraulic design of components for future HLM Fast Reactors. The CIRCulation Eutectic (CIRCE) is a pool type experimental facility working with Lead Bismuth Eutectic (LBE) as coolant (total inventory up to 90 tons). Inside the CIRCE vessel, the test section named Integral Circulation Experiments (ICE) was hosted and operated in order to investigate thermal hydraulic phenomena occurring during abnormal conditions (Protected Loss Of Heat Sink with Loss Of Flow Accident (PLOHS+LOFA)). This document describes the achieved experimental results of the proposed experimental campaign for the full power steady state condition (normal operation conditions) and for the transient phase (transition to decay heat removal conditions). Experimental data relating to thermal hydraulic phenomena such as the modification of the thermal stratification in "pool type" configuration, coolant mass flow rate modification in the test section occurring during the simulation of the designed accidental conditions and the capability to cool the 37-pins fuel bundle under natural circulation conditions are here reported and described.
\end{abstract}

\section{INTRODUCTION}

Nowadays, numerical modelling and simulations play more and more a key role in the design and development of components and complete systems. For the Heavy Liquid Metal (HLM) cooled nuclear reactors, new software tools and models are being developed to investigate the thermal-hydraulics of such reactors operating under various conditions. To be able to use these tools though for safety analyses, they need to be properly validated.

The activity proposed within the thermal-hydraulics Simulations and Experiments for the Safety Assessment of MEtal cooled reactors (SESAME) WP3 "Pool Thermal Hydraulics" of the research and innovation program HORIZON2020, is aimed to define, implement and carry out experimental campaigns on the CIRCE experimental facility (Bandini et al., 2011) in order to support the qualification of CFD as a valid tool for the design, control and analysis of complex three dimensional convection patterns in a large pool configuration simulating the primary system of a LBE- LEAD cooled reactor.

In this document, the experimental activity on the CIRCE-ICE pool type facility is summarized and the outcomes of the performed experimental tests are reported. The proposed experimental test matrix was intended to reproduce steady state forced circulation at full power and steady state natural circulation at decay power (5-7\% of the nominal power). Moreover, the transition from forced to natural circulation was also investigated simulating a Protected Loss of Heat Sink with Loss of Flow Accident (PLOHS+LOFA) scenario.

\section{NOMENCLATURE}

$\begin{array}{ll}\text { CFD } & \text { Computational Fluid Dynamic } \\ \text { CIRCE } & \text { Circolazione Eutettico } \\ \text { DHR } & \text { Decay Heat Removal system } \\ \text { FPS } & \text { Fuel Pin Simulator } \\ \text { HLM } & \text { Heavy Liquid Metal } \\ \text { HX } & \text { Heat Exchanger } \\ \text { ICE } & \text { Integral Ciculation Experiment } \\ \text { LBE } & \text { Lead Bismuth Eutectic } \\ \text { LOFA } & \text { Loss Of Flow Accident } \\ \text { Nu } & \text { Nusselt number } \\ \text { Pe } & \text { Peclet number } \\ \text { PLOFA } & \text { Protected Loss of Flow Accident } \\ \text { PLOHS } & \text { Protected Loss Of Heat Sink } \\ \text { SESAME } & \text { thermal-hydraulics Simulations and Experiments for the Safety Assessment of MEtal cooled reactors }\end{array}$


This is the Author's Generated Preprint of an article published in NUCLEAR ENGINEERING AND DESIGN and available online at the following link:

https://doi.org/10.1016/j.nucengdes.2019.110307

\section{CIRCE FACILITY AND ICE TEST SECTION}

CIRCE (CIRcolazione Eutettico) (Bandini et al. 2001, Tarantino et al. 2011, Tarantino et al. 2015) is an integral effect pool type facility designed and realized at the ENEA Brasimone Research Centre consisting of a cylindrical vessel (Main Vessel S100) filled with about 70 tonnes of molten lead-bismuth eutectic (LBE) with argon cover gas and recirculation system, LBE heating and cooling systems, several test sections welded to and hung from bolted vessel heads for separate effects and integral testing and auxiliary equipment for eutectic circulation (Turroni et al., 2001; Benamati et al., 2005; Tarantino and Scaddozzo, 2006; Bandini et al., 2001). The facility is completed by an LBE storage tank (S200), a small LBE transfer tank (S300) and a data acquisition system During the loading operations, the LBE is gradually transferred from the storage tank (S200) to the S300 vessel. Then, by pressurization of the S300 cover gas, the liquid metal gradually fills the test vessel (S100) from the bottom.

The main vessel S100 is $8500 \mathrm{~mm}$ high, and it is connected by valves to the other vessels. It is externally equipped with electrical heating cables, installed at the bottom and on the lateral surface. This heating system operates in a temperature range of $200-400^{\circ} \mathrm{C}$.

A skimming line and a passive pressure safety system are also present in the main vessel, to guarantee the LBE top level and to prevent accidental overpressure. The ICE test section is contained in the S100 main vessel (see Figure 1 (a) and (b)) and consists of the following main components: downcomer, feeding conduit, flow meter, Fuel Pin Simulator (FPS), fitting volume, riser, separator, heat exchanger, dead volume and Decay Heat Removal System (DHR). The latter corresponds to the heat sink of the system in the case of DHR scenario, when the HX is unavailable. It is hydraulically de-coupled by the primary system being placed into the downcomer, designed to have a thermal duty of $40 \mathrm{~kW}$ which is about $5 \%$ of the ICE nominal power $(800 \mathrm{~kW})$ and it is fed by air at atmospheric pressure. The detailed description of the facility and the instrumentation is reported in Martelli D., 2015, SESAME WP3 "Pool Thermal Hydraulics".

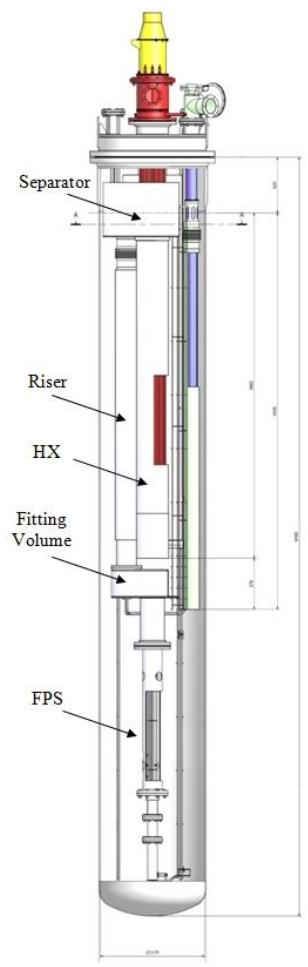

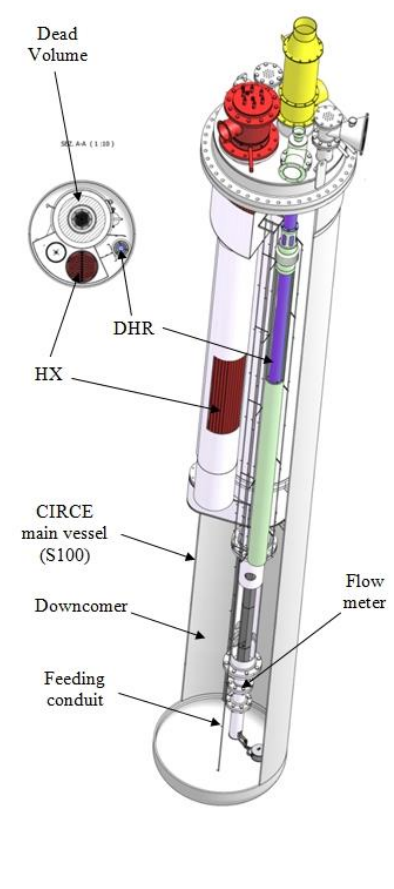

(a)

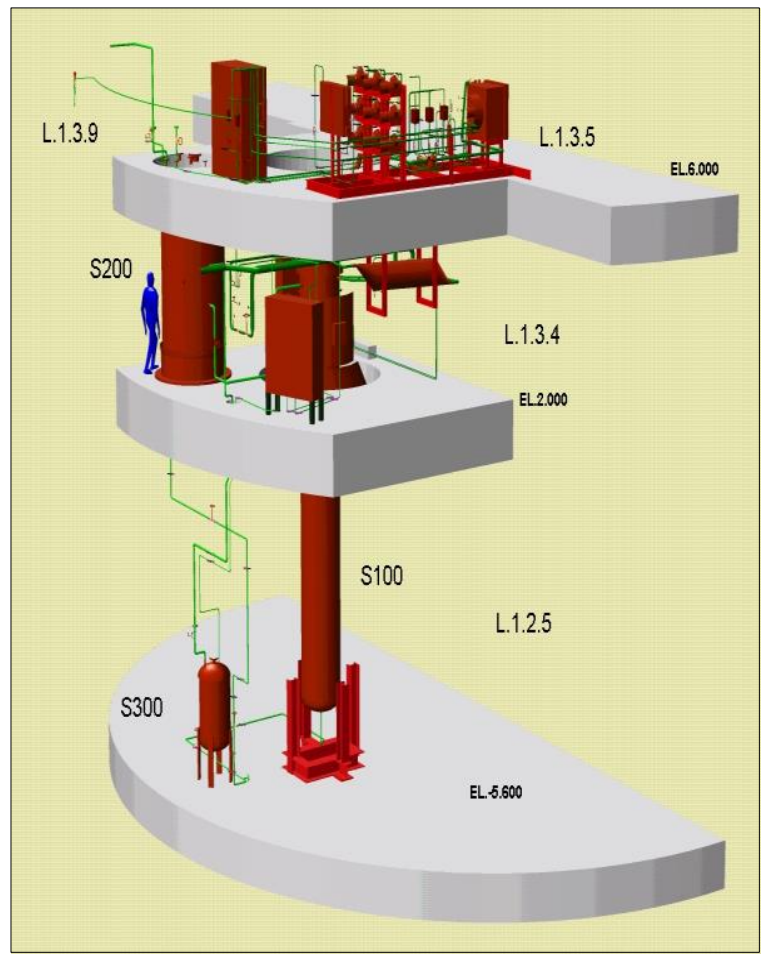

(b)

Figure 1: CIRCE-ICE facility

\section{SESAME TEST MATRIX}

The experimental activity conceived in the frame of the SESAME project consists of a series of four tests (named Test 1, Test 2, Test 3 and Test 4) simulating the total loss of the secondary circuit and the coolant pump trip (simulated stopping the gas-enhanced circulation, with the exception of Test 4) with the consequent reactor scram (reduction of the electric power supplied to the fuel pin simulator) and activation of DHR system to remove the decay heat power ( $\sim 5 \%$ of the nominal value). The boundary conditions of the performed tests are reported from Table 1 to Table 4. 
This is the Author's Generated Preprint of an article published in NUCLEAR ENGINEERING AND DESIGN and available online at the following link:

https://doi.org/10.1016/j.nucengdes.2019.110307

Table 1: Boundary conditions for TEST 1

\begin{tabular}{cc}
\hline Nominal Steady State & PLOHS+LOF transient \\
\hline HS Thermal Power $\sim 800 \mathrm{~kW}$ & Isolation of the main HX (isolating the feed water) \\
HLM flow rate: $60-70 \mathrm{~kg} / \mathrm{s}$ (by gas lift) & Core "scram" at about $30 \mathrm{~kW}$ (decay power) \\
Argon mass flow rate $\sim 2.53 \mathrm{NI} / \mathrm{s}$ & $\begin{array}{c}\text { Start-up of the DHR-system } \\
\text { (air mass flow rate } 0.24 \mathrm{~kg} / \mathrm{s} \text { ) }\end{array}$ \\
Average velocity into the $\mathrm{HS}: 1 \mathrm{~m} / \mathrm{s}$ & DHR air inlet @ room temperature \\
Pool LBE initial temperature $~ 314^{\circ} \mathrm{C}$ & "Main pump" turn-off \\
(Vertical gradient in the pool of $3^{\circ} \mathrm{C}$ ) & (the gas injection is interrupted) \\
Vessel heating system: not active & Vessel heating system: not-active \\
HX water flow rate $~ 0.6 \mathrm{~kg} / \mathrm{s}$ & \\
HX thermal power removed $\sim 750 \mathrm{~kW}$ & \\
DHR: not active & \\
\hline
\end{tabular}

Table 2: Boundary conditions for TEST 2

\begin{tabular}{cc}
\hline Nominal Steady State & PLOHS+LOF transient \\
\hline HS Thermal Power $~ 600 \mathrm{~kW}$ & Isolation of the main HX (isolating the feed water) \\
HLM flow rate: $60-70 \mathrm{~kg} / \mathrm{s}$ (by gas lift) & $\begin{array}{c}\text { Core “scram" at about } 30 \mathrm{~kW} \text { (decay power) } \\
\text { Start-up of the DHR-system }\end{array}$ \\
Argon mass flow rate $\sim 2.7 \mathrm{NI} / \mathrm{s}$ & (air mass flow rate $0.325 / 0.22 \mathrm{~kg} / \mathrm{s}$ ) \\
Average velocity into the $\mathrm{HS}: 1 \mathrm{~m} / \mathrm{s}$ & DHR air inlet @ room temperature \\
Pool LBE initial temperature $~ 280^{\circ} \mathrm{C}$ & "Main pump" turn-off \\
(Vertical gradient in the pool of $4^{\circ} \mathrm{C}$ ) & (the gas injection is interrupted) \\
Vessel heating system: not active & Vessel heating system: not-active \\
HX water flow rate $0.6 \mathrm{~kg} / \mathrm{s}$ & \\
HX thermal power removed $\sim 500 \mathrm{~kW}$ & \\
DHR: not active & \\
\hline
\end{tabular}

Table 3: Boundary conditions for TEST 3

\begin{tabular}{cc}
\hline Nominal Steady State & PLOHS+LOF transient \\
\hline HS Thermal Power $\sim 750 \mathrm{~kW}$ & Isolation of the main HX (isolating the feed water) \\
HLM flow rate: $59.6 \mathrm{~kg} / \mathrm{s}$ (by gas lift) & Core "scram" at about $30 \mathrm{~kW}$ (decay power) \\
Argon mass flow rate $\sim 2.5-2.6 \mathrm{NI} / \mathrm{s}$ & $\begin{array}{c}\text { Start-up of the DHR-system } \\
\text { (air mass flow rate } 0.2 \mathrm{~kg} / \mathrm{s} \text { ) }\end{array}$ \\
Average velocity into the $\mathrm{HS}: 0.91 \mathrm{~m} / \mathrm{s}$ & DHR air inlet @ room temperature \\
Pool LBE initial temperature $~ 270^{\circ} \mathrm{C}$ & "Main pump" turn-off \\
(Vertical gradient in the pool of $1-2^{\circ} \mathrm{C}$ ) & (the gas injection is interrupted) \\
Vessel heating system: not active & Vessel heating system: not-active \\
HX water flow rate $\sim 0.5 \mathrm{~kg} / \mathrm{s}$ & \\
HX thermal power removed $\sim 411 \mathrm{~kW}$ & \\
DHR: not active &
\end{tabular}

Table 4: Boundary conditions for TEST 4

\begin{tabular}{cc}
\hline Nominal Steady State & PLOHS transient \\
\hline HS Thermal Power $\sim 750 \mathrm{~kW}$ & $\begin{array}{r}\text { Isolation of the main HX (isolating the feed water) } \\
\text { Core "scram" at about } 30 \mathrm{~kW} \text { (decay power) }\end{array}$ \\
HLM flow rate: $56.4 \mathrm{~kg} / \mathrm{s}-53.3 \mathrm{~kg} / \mathrm{s}$ & $\begin{array}{c}\text { Start-up of the DHR-system } \\
\text { (air mass flow rate } 0.2 \mathrm{~kg} / \mathrm{s} \text { ) }\end{array}$ \\
Argon mass flow rate $\sim 2.6-2.75 \mathrm{NI} / \mathrm{s}$ & DHR air inlet @ room temperature \\
Average velocity into the $\mathrm{HS}: 1 \mathrm{~m} / \mathrm{s}$ & Gas injection is NOT interrupted \\
Pool LBE initial temperature $\sim 280^{\circ} \mathrm{C}$ & Vessel heating system: not-active \\
(Vertical gradient in the pool of $4^{\circ} \mathrm{C}$ ) & \\
Vessel heating system: not active & \\
HX water flow rate $0.6 \mathrm{~kg} / \mathrm{s}$ & \\
HX thermal power removed $\sim 411 \mathrm{~kW}$ & \\
DHR: not active &
\end{tabular}


This is the Author's Generated Preprint of an article published in NUCLEAR ENGINEERING AND DESIGN and available online at the following link:

https://doi.org/10.1016/j.nucengdes.2019.110307

Test 1 and Test 2 differ essentially for the thermal power supplied by the FPS ( $800 \mathrm{~kW}$ vs $600 \mathrm{~kW})$ while Test 3 and Test 4 differs by the fact that for Test 4 the forced circulation is maintained also after the transition to reduced power condition. Moreover, Test 1 and Test 2 are short runs while Test 3 and Test 4 are long runs for a total experimental time of about 320 h. Hereafter experimental data obtained for Test 1 and Test 2 are discussed. The description of all the tests is reported in Martelli et al., SESAME D3.2 deliverable.

\section{EXPERIMENTAL RESULTS}

\subsection{Test 1}

Test 1 is characterized by a nominal power ramp from 0 to $800 \mathrm{~kW}$. The mean value of the power during the full power transient is about $804.8 \mathrm{~kW}$ with a standard deviation of $7.1 \mathrm{~kW}$. The "full power" transient stops at $\mathrm{t}=37128 \mathrm{~s}$ (about $10 \mathrm{~h}$ ) with a descending ramp up to about $30 \mathrm{~kW}(\mathrm{t}=37332 \mathrm{~s})$. The end of the low power run is at $\mathrm{t}=72339 \mathrm{~s}(\sim 20 \mathrm{~h})$. The mean value of the power after the simulation of the core scram is $30.7 \mathrm{~kW}$ with a standard deviation of $0.5 \mathrm{~kW}$.

During the full power transient, the main heat exchanger is fed by a water mass flow rate with a mean value of $0.59 \mathrm{~kg} / \mathrm{s}$ and a standard deviation of 0.02 .

After the simulation of the accidental scenario, the water injection is stopped at about $t=37265$ s. During the full power run, the LBE is circulated by means of argon gas injection (gas-enhanced circulation) with a mean value of $2.53 \mathrm{Nl} / \mathrm{s}$ and a standard deviation is $0.0347 \mathrm{Nl} / \mathrm{s}$.

After the simulation of the postulated accident, with the reduction of the power to the decay heat $(\sim 7 \%$ of the nominal power) the decay heat removal system (DHR) is activated injecting air in the bayonet tube of the DHR (227.3 $\mathrm{g} / \mathrm{s}$ with a standard deviation of 57 $\mathrm{g} / \mathrm{s})$.

LBE from the pool enters the feeding conduit of the ICE test section and the mass flow rate, measured by a venturi flow meter, is reported in Figure 2: the value reached under forced circulation condition is about $66-67 \mathrm{~kg} / \mathrm{s}$ while it is reduced to about 5-6 kg/s under natural circulation condition.

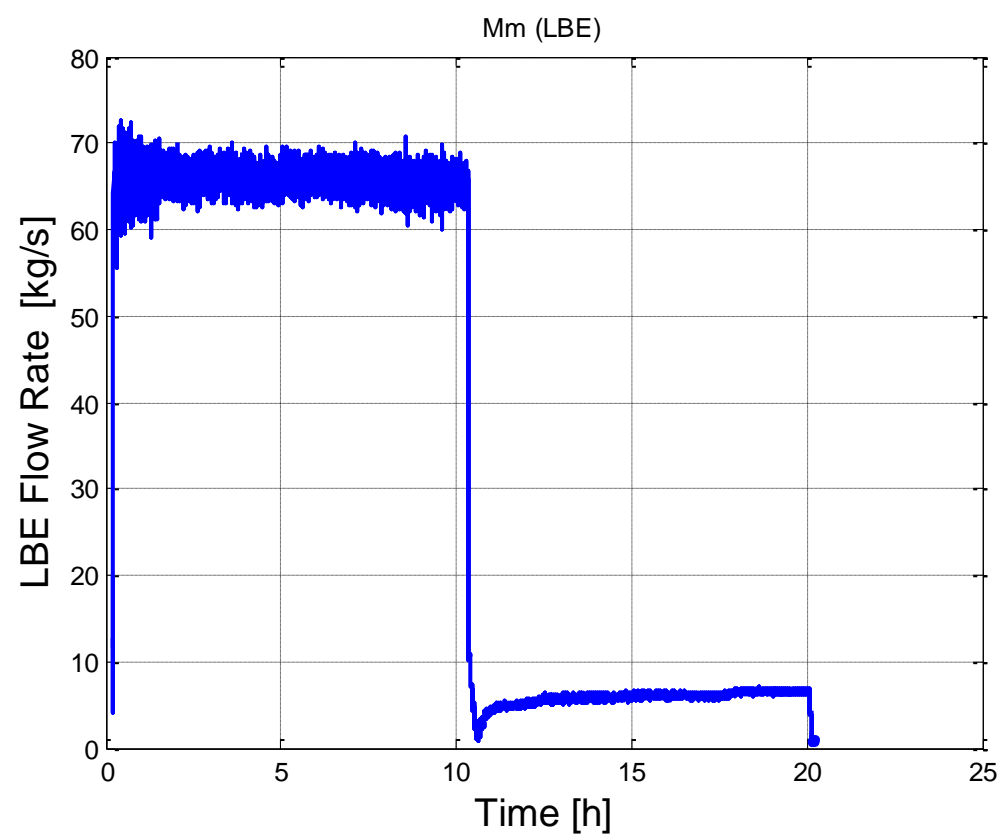

Figure 2: LBE mass flow rate in the ICE test section

The temperature of the LBE at the inlet/outlet section of the active length of the fuel pin simulator (FPS) and at the outlet section of the FPS (inside the fitting volume) are reported in Figure 3. The $\Delta \mathrm{T}$ across the active length of the FPS is about $78^{\circ} \mathrm{C}$ at full power condition while it reduces to about $32^{\circ} \mathrm{C}$ under decay heat conditions. Moreover, the temperature difference from the end of the active length and that at the end of the FPS is about $3^{\circ} \mathrm{C}$ at full power condition and about $14^{\circ} \mathrm{C}$ in decay heat condition showing a heat transfer from the LBE inside the FPS section to the LBE in the external pool. 
This is the Author's Generated Preprint of an article published in NUCLEAR ENGINEERING AND DESIGN and available online at the following link:

https://doi.org/10.1016/j.nucengdes.2019.110307

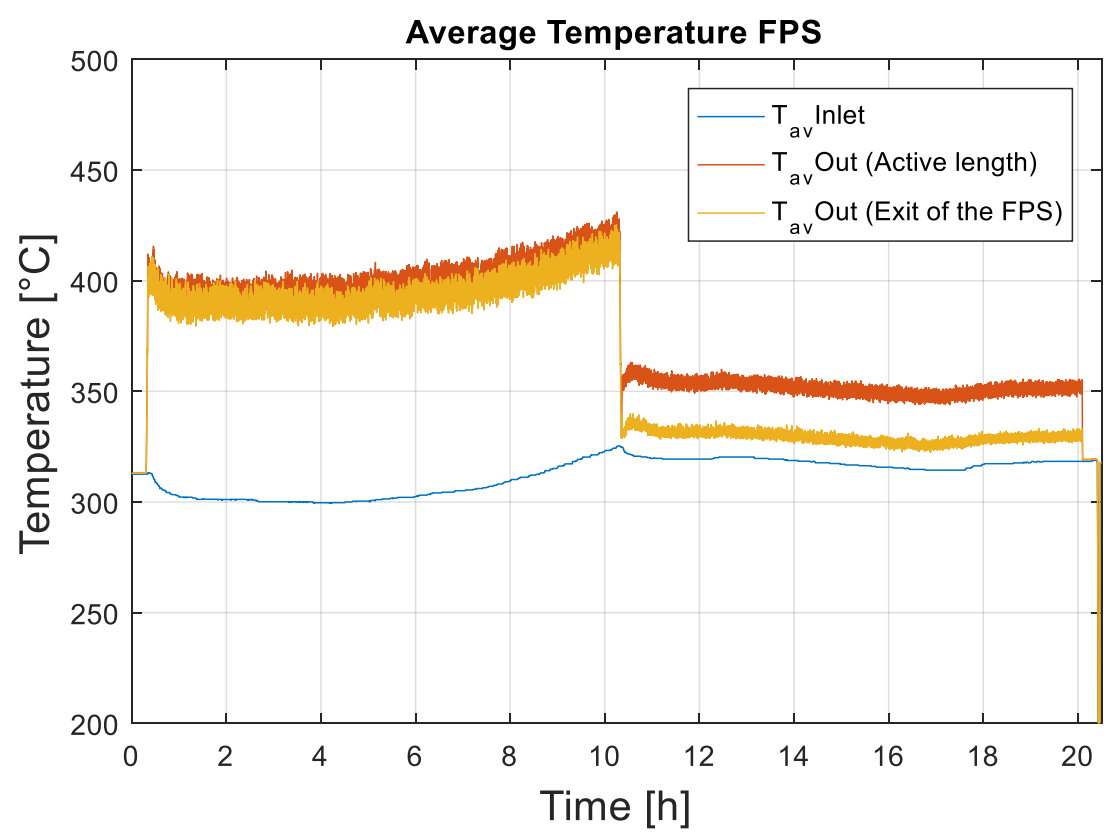

Figure 3: Active length Inlet/Outlet section and FPS Outlet LBE temperature

The LBE heated by the FPS flows through the fitting volume into the riser; here the LBE temperature is measured at the inlet and outlet sections (see Figure 4). The double wall structure of the riser with air in the annulus between the concentric pipe ensures the thermal decoupling between the LBE in the riser and the LBE in the external pool, and temperature differences between the inlet and outlet sections is negligible for both full power and decay heat conditions. Furthermore, Figure 4 shows that there is a plateau in the temperature field in the first $5 \mathrm{~h}$ of the "full power phase" (se also Figure 10) followed by a subsequent rise in temperature while the supplied/removed power is the same during this whole period. This behaviour can be explained considering the thermal inertia of the internal metallic structures. In the first $5 \mathrm{~h}$ a percentage of the supplied power is absorbed by the structures themselves. Once the thermal balance between the LBE and the structures is reached, then the LBE temperature starts to increase again.

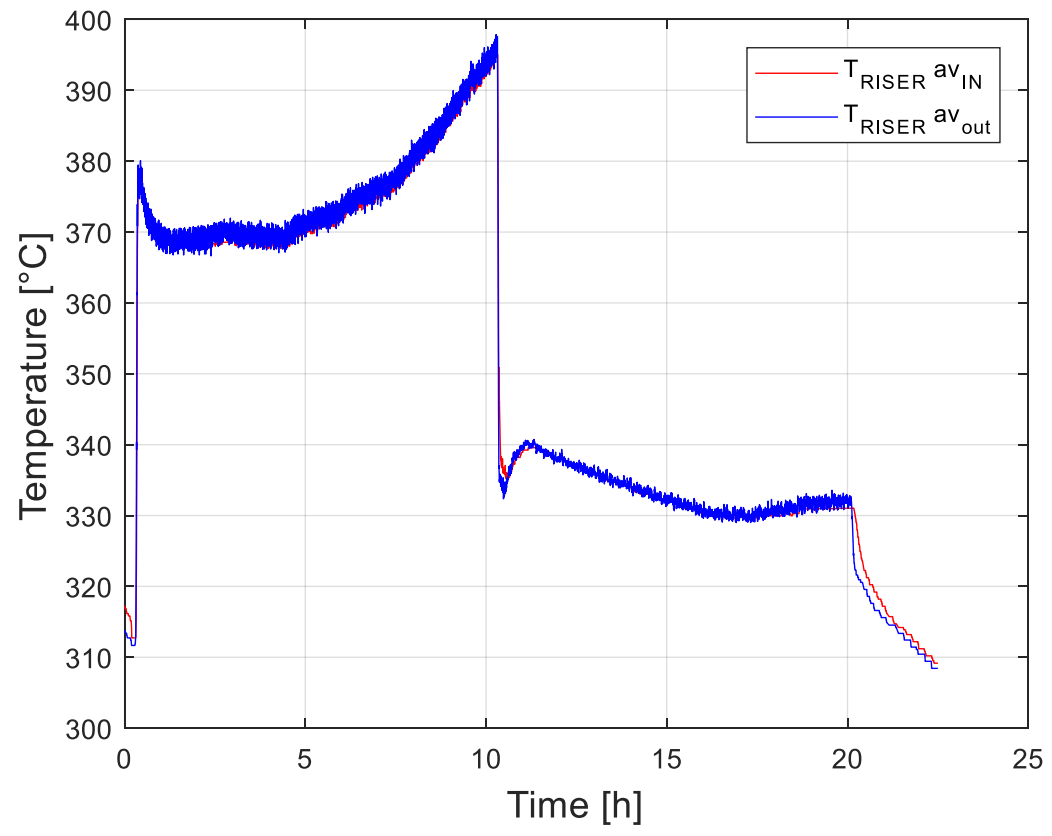

Figure 4: LBE Inlet/Outlet temperature in the riser

From the exit section of the riser, the LBE flows through the separator into the HX (shell side) and here the LBE is cooled by the water/steam flowing in the 91 tubes of the heat exchanger. The temperature time-trends at the inlet/outlet sections of the HX are reported in Figure 5. The LBE inlet/outlet temperature difference across the $\mathrm{HX}$ is about $78^{\circ} \mathrm{C}$ during full power while after the de-activation of the heat exchanger the difference decreased to about $4{ }^{\circ} \mathrm{C}$ due to the heat losses toward the pool side. 
This is the Author's Generated Preprint of an article published in NUCLEAR ENGINEERING AND DESIGN and available online at the following link:

https://doi.org/10.1016/j.nucengdes.2019.110307

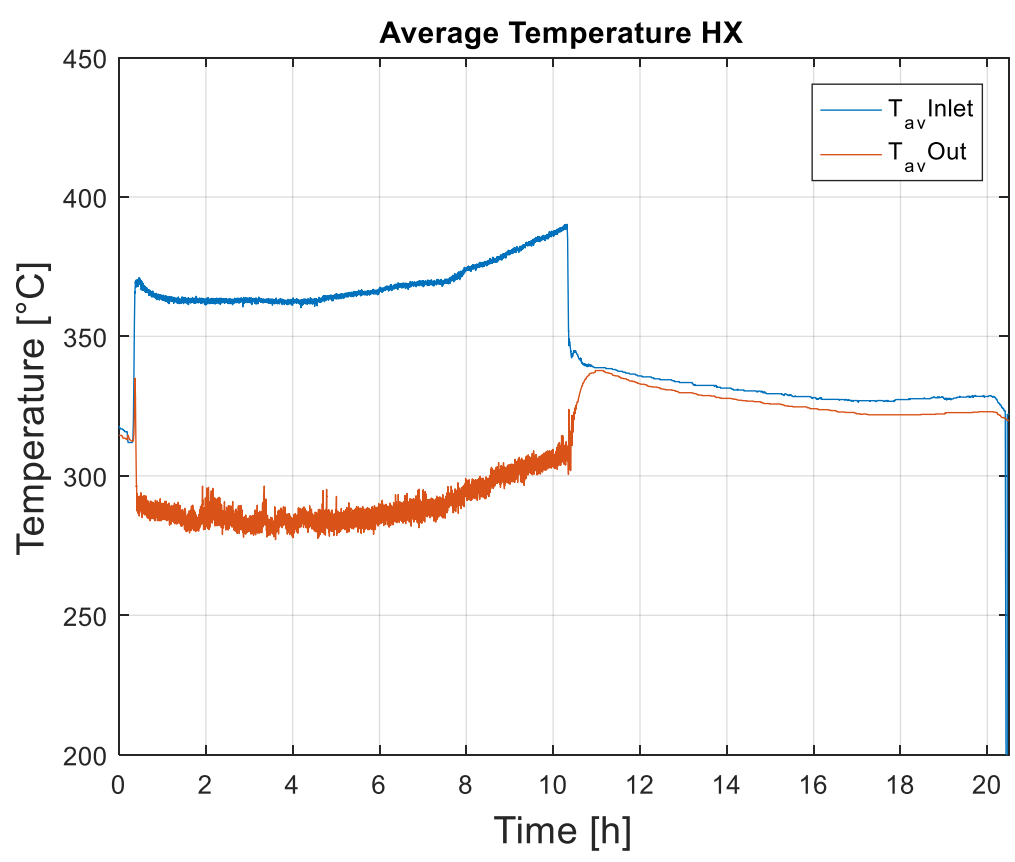

Figure 5: LBE Inlet/Outlet temperature in the HX

The thermal power removed by the HX is evaluated by a thermal balance (LBE side) and reported in Figure 6. Before the simulated transient, the power removed is about $750 \mathrm{~kW}$. From the exit section of the heat exchanger, the LBE enters in the LBE pool (S100).

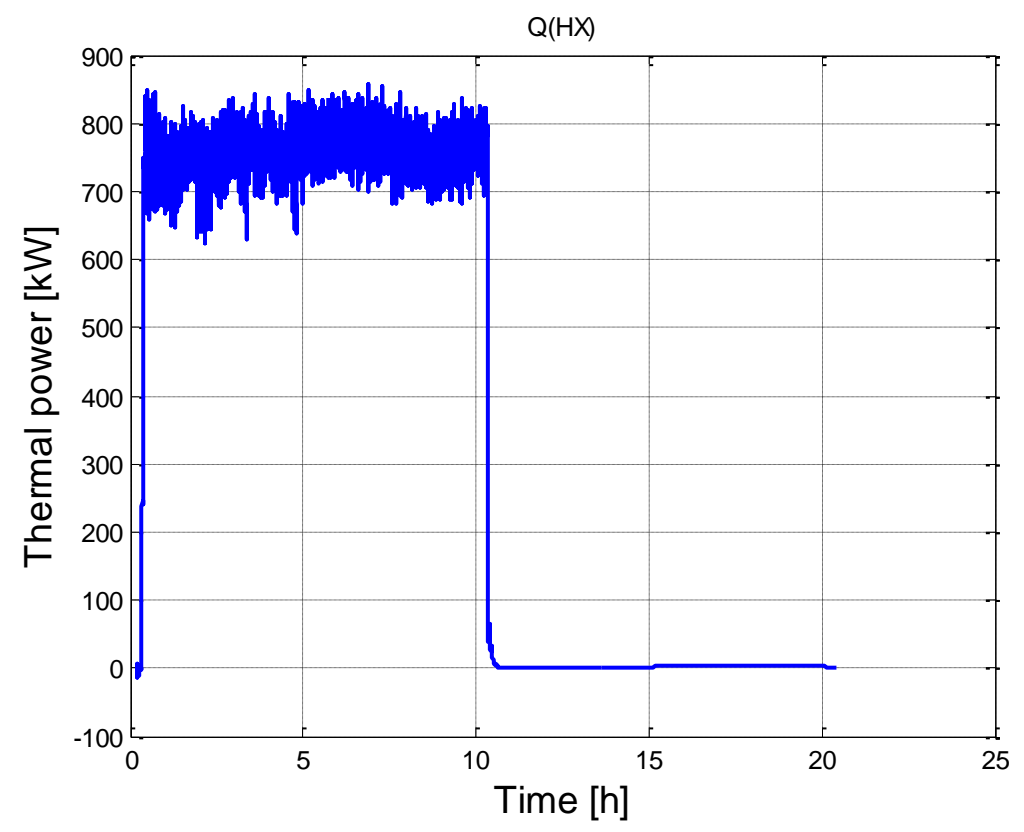

Figure 6: Thermal Power removed by the $H X$

After the simulation of the PLOHS+LOFA accidental scenario, the feedwater system and the argon injection are switched off to simulate the loss of the secondary side water system and the pump trip. At the same time, the power supplied to the FPS is reduced to the $5-7 \%$ of the nominal power to simulate the decay heat and the DHR system is activated.

To investigate the thermal stratification inside the large LBE pool all the 119 TCs installed in the pool region of the vessel are reported as function of the axial depth (Tarantino et al.,2015) at four different times: at the beginning of the test, at the steady state of the full power, at the steady-state of the DHR phase. Height different radial position are reported in Figure 8 (from Line A up to Line F). The radial displacement of TCs supporting roads is shown in Figure 7. 
This is the Author's Generated Preprint of an article published in NUCLEAR ENGINEERING AND DESIGN and available online at the following link:

https://doi.org/10.1016/j.nucengdes.2019.110307

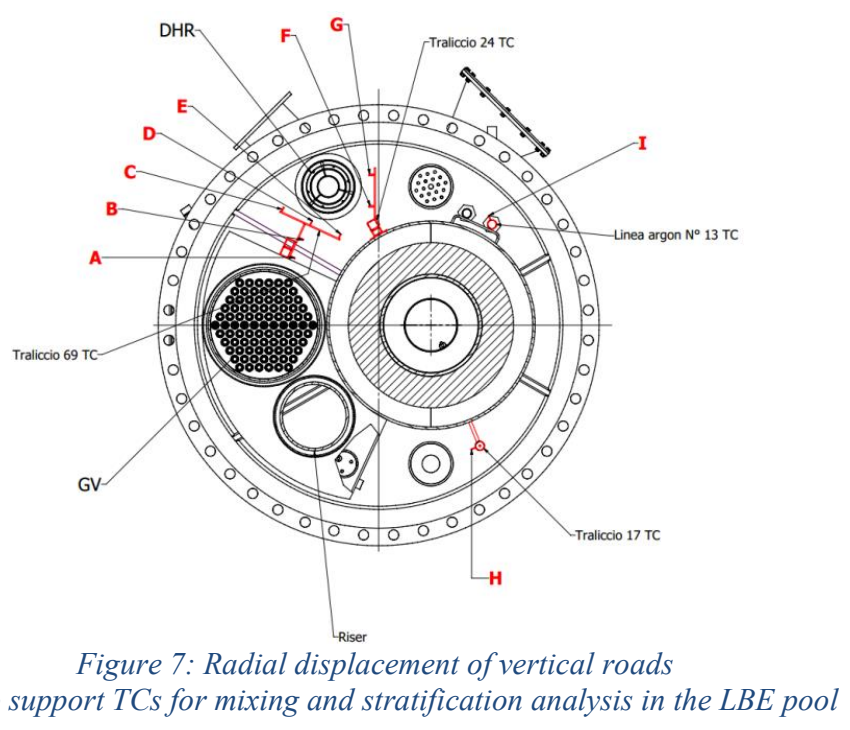

At the beginning of the experimental test (see Figure 8 (a)), the LBE temperature is quite uniform inside the pool assuming an average value of about $313^{\circ} \mathrm{C}$ unvarying in each radial section of the vessel (i.e. at $\mathrm{z}$ fixed and different radial position). At the end of the full power phase (forced circulation conditions after about $9.4 \mathrm{~h}$ ) thermal stratification phenomena are evident inside the pool, with a thermal gradient of about $40^{\circ} \mathrm{C}$ in the first $3.5 \mathrm{~m}$ (up to the outlet section of the $\mathrm{HX}$ ), see Figure 8 (b). Then, there is a region between the outlet sections of the HX and the DHR were the slope of the thermal gradient increases with a temperature difference of about $20^{\circ} \mathrm{C}$ in $0.5 \mathrm{~m}$. In the lower part of the pool (from the inlet section of the ICE test section to the bottom of the vessel), the temperature is uniform with a value of about $318^{\circ} \mathrm{C}$. The $\mathrm{LBE}$ exits the $\mathrm{HX}$ at about $300^{\circ} \mathrm{C}$ (after $9.4 \mathrm{H}$ from the beginning of the test), about $20^{\circ} \mathrm{C}$ lower than the temperature of the LBE in the lower plenum. It is in the author opinion the LBE cold plume cannot deeply penetrate in the lower plenum because of the heat losses from the test section (fitting volume and upper part of the FPS) and the mixing with the LBE of the pool.

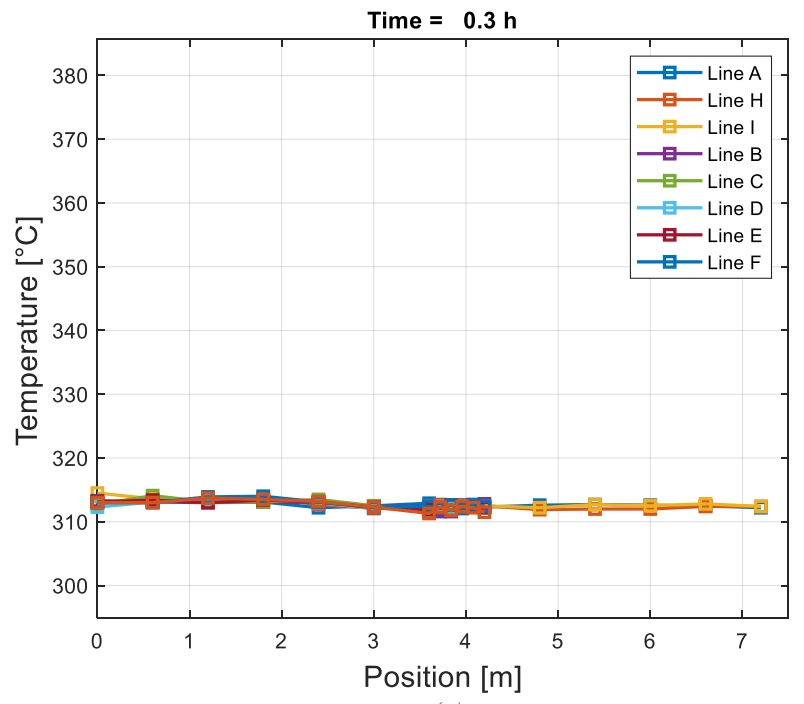

(a)

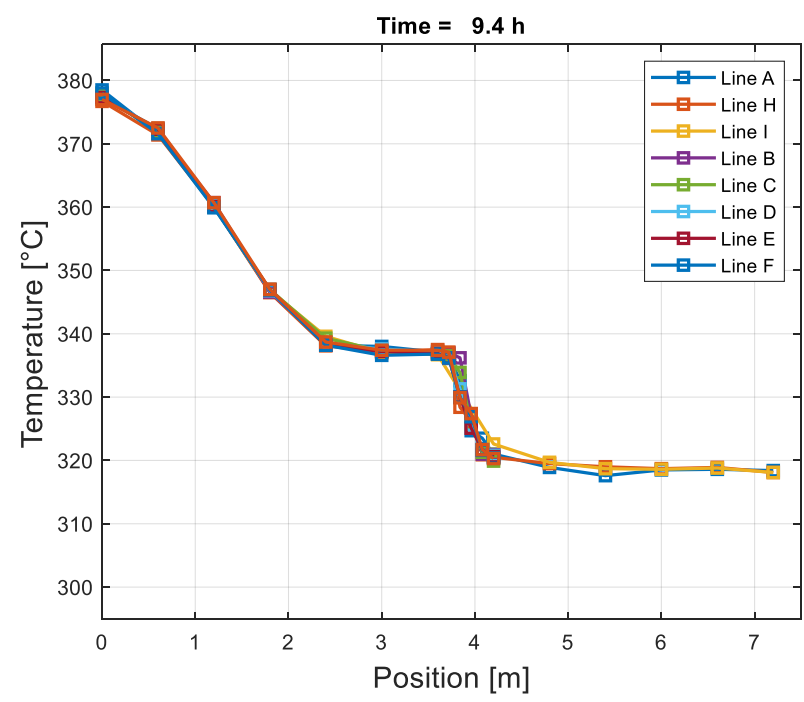

(b)

Figure 8: LBE temperature in the pool

After the transition to natural circulation conditions, the temperature field significantly changes. In the upper and lower parts of the vessel the LBE temperature is uniform with a layer separating the two zones where the thermal gradient concentrates. That area, after the transition from forced to natural circulation, moved downwards below the DHR outlet section and the thermal gradient reduces to about $10^{\circ} \mathrm{C}$, as can be seen comparing Figure 8 (b) and Figure 9. 
This is the Author's Generated Preprint of an article published in NUCLEAR ENGINEERING AND DESIGN and available online at the following link:

https://doi.org/10.1016/j.nucengdes.2019.110307

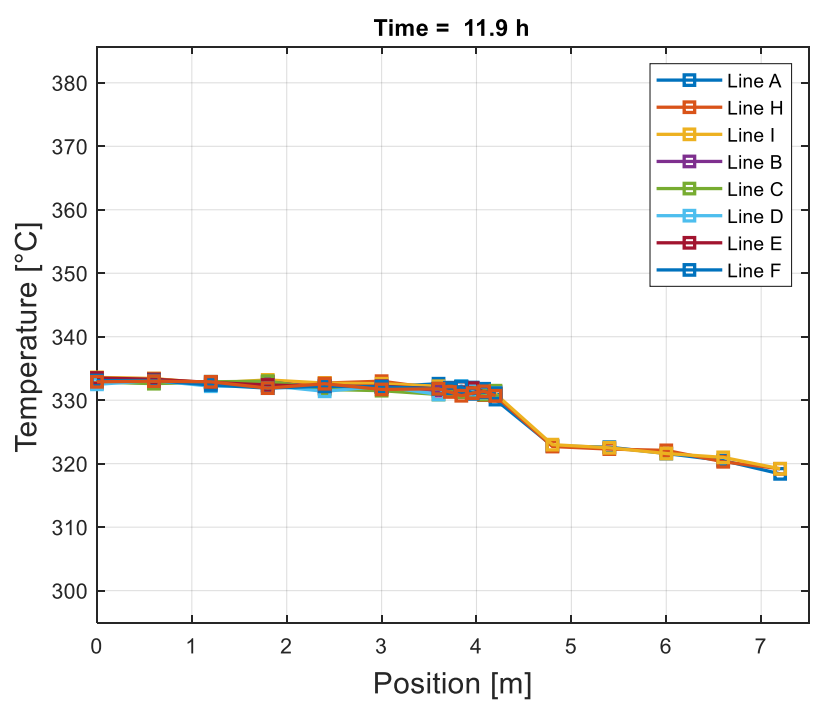

Figure 9: LBE temperature in the pool

The LBE temperature time trends along two vertical displacements, namely Line A and Line H, are reported in Figure 10 (a) and (b). It is evident the thermal gradient in the upper plenum of the pool during the full power phase. After the transition to DHR mode, the temperature field changes showing two regions (upper and lower plenum) at constant temperature separated by a small region where thermal gradients are confined.

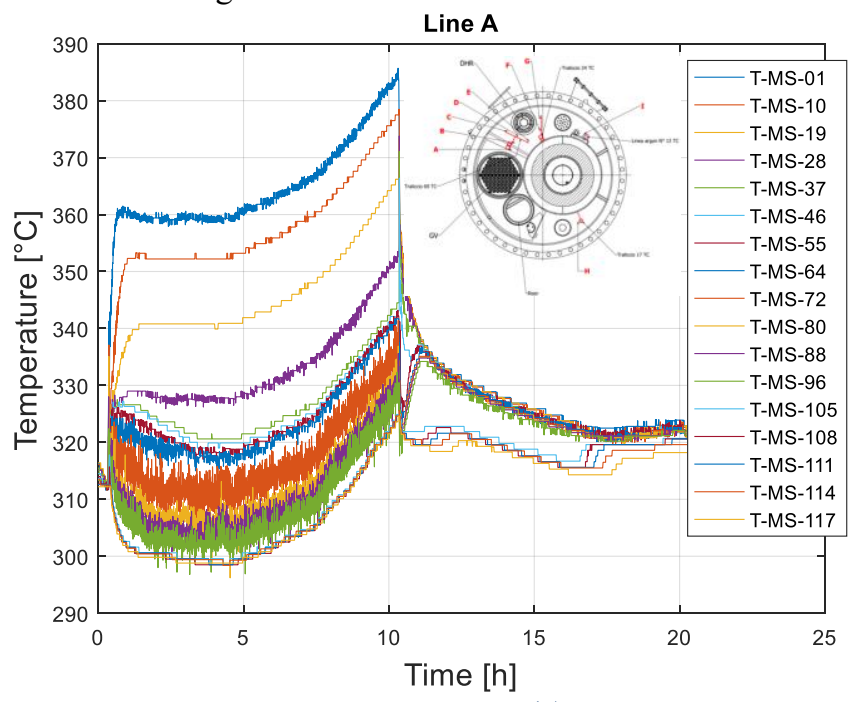

(a)

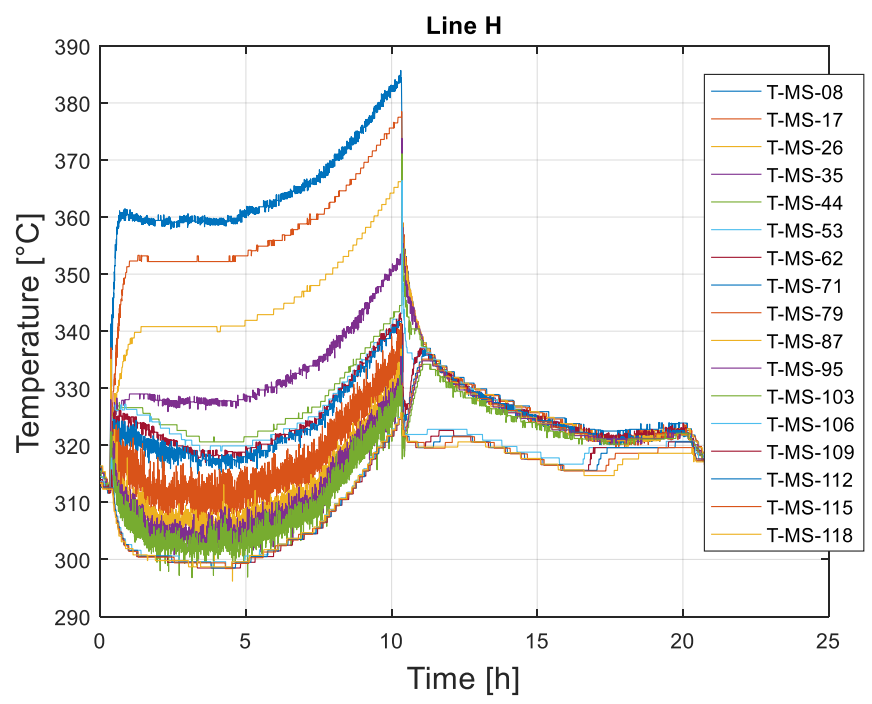

(b)

Figure 10: DHR inlet section before (a) and after (b) the experimental campaign

\subsection{Test 2}

Referring to the experimental test Test 2 (see Table 2) Nu number is calculated from the experimental data in the central subchannel (see Figure 10 (a)) of the FPS according to Martelli et al., 2015 (Nucl. Eng. And Des.) and obtained results are compared with $\mathrm{Nu}$ values obtained from Ushakov et al. 1977, and Mikytiuk, 2009 correlations. The main experimental primary variables are summarized in Table 5. For the Nu calculation, the bulk temperature on the middle and upper Sections (20 mm upstream the middle spacer grid and $60 \mathrm{~mm}$ upstream the upper spacer grid respectively, see Figure 13 (b)) is obtained assuming a linear trend between the average temperature values at the entrance and at the exit of the FPS active length. Moreover, concerning the bulk temperature $\left(T_{C C}\right)$, the values reported in Table 5 are obtained from the local thermocoules and applying a correction to take into account the thermal conduction phenomena in the diameter of the thermocouple (the position of the thermocouple is fixed to the pin external wall with an AISI 304 sheet, Martelli D., 2015. CIRCE reference document). In particular, the LBE mass flow rate flowing through the bundle is reported together with temperatures in the centre of the channel and on the considered pin (Pin 1 central and 7 in the first rank). Moreover, the standard deviation is reported for each variable accounting the effect of the uncertainty in single measurements on the calculated results in agreement with Lichten, 1999 and Moffat, 1988. In

Table 5 the average temperatures at the inlet and outlet sections of the FPS are also reported. 


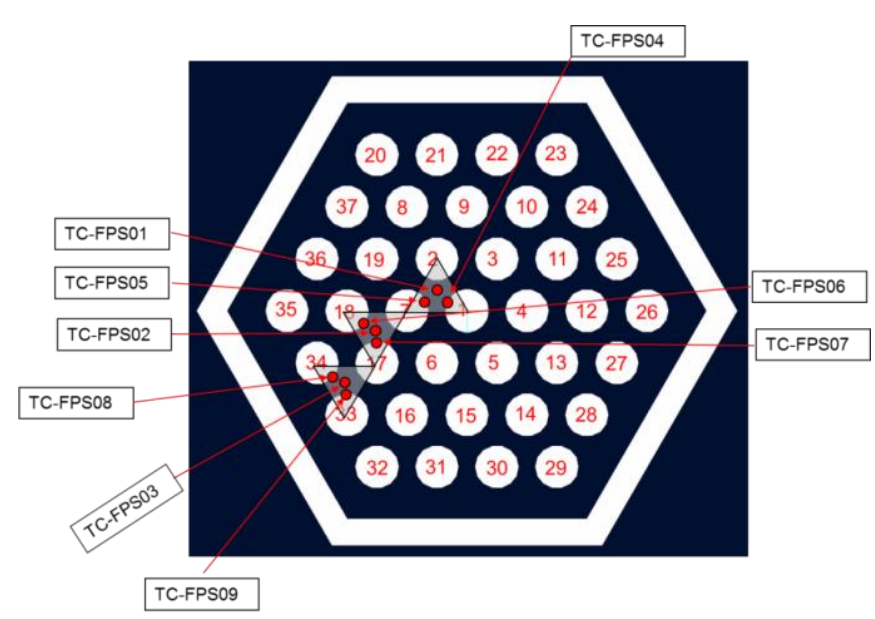

(a)

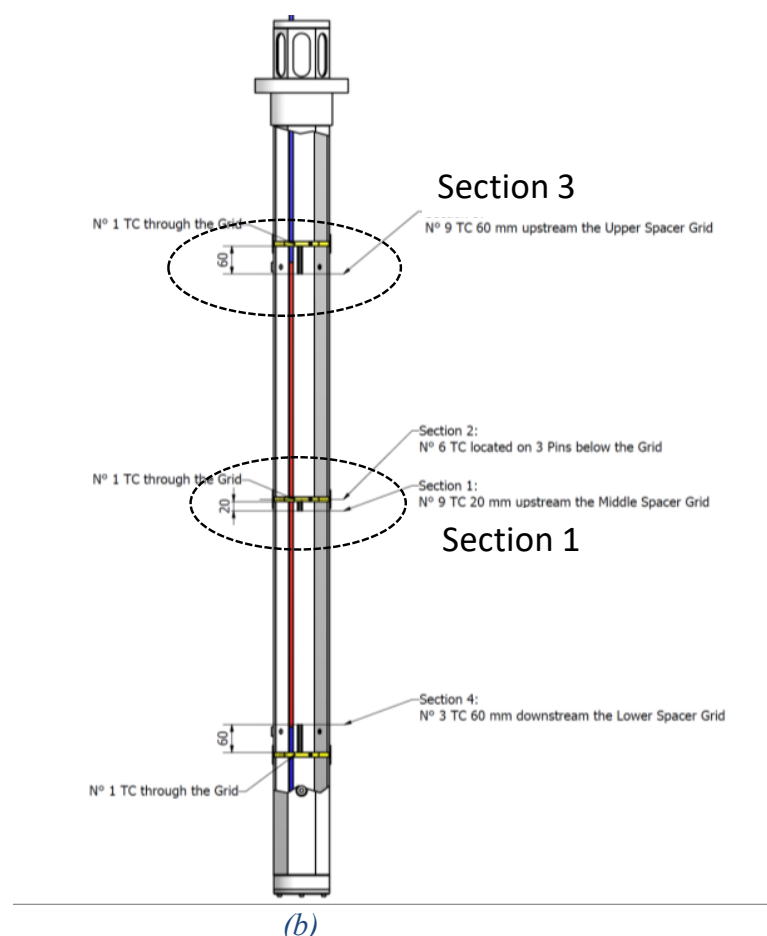

(b)

Figure 11: TCs arrangement in the central subchannel of the FPS (a) and instrumented sections (b)

Table 5: Primary variables and their uncertainties

\begin{tabular}{|c|c|c|c|c|c|c|c|c|c|c|c|c|}
\hline Name & $\begin{array}{c}\mathrm{mfrs} \\
{[\mathrm{kg} / \mathrm{s}]}\end{array}$ & $\begin{array}{c}\left\langle\sigma_{X}\right\rangle \\
{[\mathrm{kg} / \mathrm{s}]}\end{array}$ & $\begin{array}{l}\bar{T}_{C C} \\
{\left[{ }^{\circ} \mathbf{C}\right]}\end{array}$ & $\begin{array}{c}\left\langle\sigma_{X}\right\rangle \\
{\left[{ }^{\circ} \mathbf{C}\right]}\end{array}$ & $\begin{array}{l}\bar{T}_{P i n 1} \\
{\left[{ }^{\circ} \mathrm{C}\right]}\end{array}$ & $\begin{array}{c}\left\langle\sigma_{X}\right\rangle \\
{\left[{ }^{\circ} \mathbf{C}\right]}\end{array}$ & $\begin{array}{c}\bar{T}_{\operatorname{Pin} 7} \\
{\left[{ }^{\circ} \mathbf{C}\right]}\end{array}$ & $\begin{array}{c}\left\langle\sigma_{X}\right\rangle \\
{\left[{ }^{\circ} \mathbf{C}\right]}\end{array}$ & $\begin{array}{l}\bar{T}_{F P S}^{i n} \\
{\left[{ }^{\circ} \mathbf{C}\right]}\end{array}$ & $\begin{array}{c}\left\langle\sigma_{X}\right\rangle \\
{\left[{ }^{\circ} \mathbf{C}\right]}\end{array}$ & $\begin{array}{l}\bar{T}_{F P S}^{\text {out }} \\
{\left[{ }^{\circ} \mathbf{C}\right]}\end{array}$ & $\begin{array}{c}\left\langle\sigma_{X}\right\rangle \\
{\left[{ }^{\circ} \mathbf{C}\right]}\end{array}$ \\
\hline Full Power Sec 1 & 67.4 & 2.1 & 301.5 & 1.5 & 344.6 & 1.7 & 343.1 & 2.3 & 279.4 & 1.9 & 342.2 & 2.65 \\
\hline Full Power Sec 3 & 67.4 & 2.1 & 335.6 & 1.7 & 382.5 & 1.7 & 368.3 & 1.6 & 279.4 & 1.9 & 342.2 & 2.65 \\
\hline Decay Power Sec 1 & 7.8 & 0.25 & 282.3 & 0.7 & 285.7 & 0.6 & 286.4 & 0.7 & 268.3 & 1.2 & 296.2 & 1.5 \\
\hline Decay Power Sec 3 & 7.8 & 0.25 & 297.9 & 0.9 & 301 & 0.8 & 301 & 0.8 & 268.3 & 1.2 & 296.2 & 1.5 \\
\hline
\end{tabular}

In Table 6 the Nu numbers computed for full power and decay power run of the experimental Tests 2 are reported together with the Pe and Re numbers. These variables are secondary variables hence the propagation of errors is calculated taking the root-sum-of-squares of all partial error to get the total error.

Table 6:Secondary variables and their uncertainties

\begin{tabular}{ccccccc}
\hline Name & Re & $\left\langle\sigma_{X}\right\rangle$ & Pe & $\left\langle\sigma_{X}\right\rangle$ & Nu & $\left\langle\sigma_{X}\right\rangle$ \\
\hline Full Power Sec 1 & $1.310^{5}$ & $7.410^{3}$ & 2885 & 261 & 27.2 & 3.5 \\
Full Power Sec 3 & $1.410^{5}$ & $7.910^{3}$ & 2786 & 252 & 24.9 & 2.9 \\
Decay Power Sec 1 & $1.410^{4}$ & 819 & 347 & 31 & 13.6 & 3.8 \\
Decay Power Sec 3 & $1.510^{4}$ & 844 & 341.5 & 31 & 8.9 & 2.2 \\
\hline
\end{tabular}

Figure 12 shows the $\mathrm{Nu}$ number computed from the experimental data as a function of the Peclet number compared with Mikityuk and Ushakov correlations. In general, a good agreement is found between the experimental data and the cited correlation.

Differences between Section 1 and Section 3 in the experimental data are due to the fact that Section1 is closer to the spacer grid than Section 3, hence heat transfer is more affected by the increased turbulence caused by the spacer grid. Moreover, as a general remark, experimental data show the tendency to lie below Nu values given by the correlations, confirming the outcomes of previous experimental campaigns (Martelli et al., 2017). 


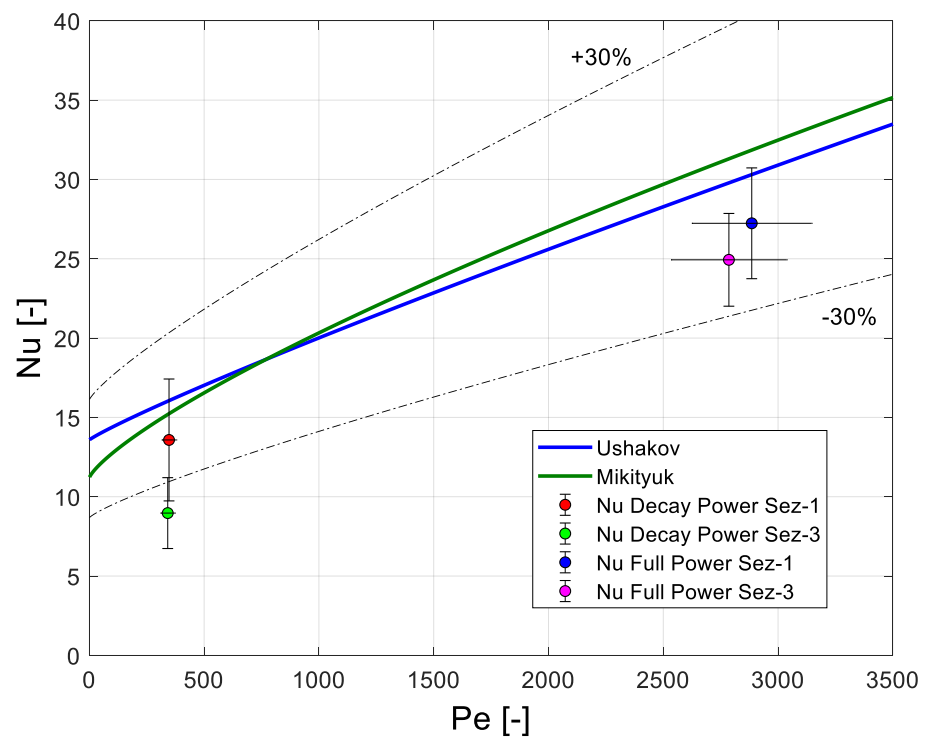

Figure 12: Experimental Nu vs. Pe number and comparison with Mikityuk and Ushakov correlations

\section{CONCLUSION}

This work describes the experimental activity performed in the framework of the work package WP3 of the H2020 SESAME project at the ENEA Brasimone Research Centre dealing with the thermal-hydraulics analysis of Heavy Liquid Metal-cooled fast reactor, aimed at their safety analysis in response to hypothetical accidental scenarios and to provide experimental data to support the qualification of CFD as a valid tool for the design, control and analysis of complex three dimensional convection patterns in a large pool configuration simulating the primary system of a LBE- LEAD cooled reactor.

A series of four experimental tests were carried out simulating the total loss of the secondary circuit and the coolant pump trip (simulated by stopping the gas-enhanced circulation, with the exception of Test 4) with the subsequent simulation of the reactor scram (reduction of the electric power supplied to the fuel pin simulator) and activation of DHR system to remove the decay heat power ( $\sim 5 \%$ of the nominal value). Tests differ from each other by the applied boundary conditions such as the electrical power supplied to the FPS, the duration of the test, the power removed by the HX etc., while test 4 also differs for the forced circulation maintained after the simulation of the accidental transient.

Concerning the thermal stratification inside the pool at the full power steady state, the experiment shows the same general behavior independently from the external conditions, characterized by the presence of a thermal gradient of about $40^{\circ} \mathrm{C}$ in the first $3.5 \mathrm{~m}$ starting from the free level (up to the outlet section of the HX). Then between the outlet sections of the HX and the DHR the slope of the vertical temperature profile increases, with a temperature drop of about $15-20^{\circ} \mathrm{C}$ in less than $1 \mathrm{~m}$. Moreover, the thermal stratification in the pool is purely vertical with negligible temperature variation on the horizontal planes. After the transition to natural circulation, the vertical temperature profile changes and the region where the thermal gradient is located moves downwards starting at the exit section of the DHR-system and is characterized by a temperature drop of about $10^{\circ} \mathrm{C}$.

Finally, the investigation on the heat transfer inside the bundle shows for Test 2 a good agreement between the Nu obtained from the experimental data and those obtained from Ushakov and Mikityuk correlations, with the experimental values being lower than the cited correlations. Almost all the calculated $\mathrm{Nu}$ values differ from $\mathrm{Nu}$ given by correlations by less than $25 \%$.

\section{ACKOWLEGMENT}

This work was performed in the framework of the H2020 SESAME project. This project has received funding from the Euratom research and training program 2014-2018 under grant agreement No 654935. 